\title{
Relato de caso: eritema multiforme em criança em idade escolar
} Case report: erythema multiforme in school-age child

Camila Voos Soares ${ }^{1}$, Cássia Pinheiro Kapper ${ }^{1}$, Francine Carla Oliveira Seibt ${ }^{1}$, Lucas Andreis', Tamilis de Almeida Machado'

'Universidade de Santa Cruz do Sul (Unisc), Santa Cruz do Sul, RS, Brasil.

Recebido em: maio 2015 / Aceito em: julho 2015

lucasandreis47@gmail.com

\section{RESUMO}

O eritema multiforme (EM) se caracteriza por uma reação imunológica que afeta pele e mucosa mais comumente observada após infecções virais, principalmente por herpes vírus (HSV). Relato de caso: paciente feminina, 8 anos, inicia com quadro de dor e edema em mãos. Evoluiu com vesículas e bolhas em tronco, dorso e face, mas em maior concentração em mãos e pés com acometimento de palmas e plantas. As bolhas eram tensas com base eritematosa e algumas com crosta. Discussão: as lesões cutâneas comumente aparecem em regiões de extremidades como mãos e pés: são planas, redondas e vermelho escuras, tendo o formato de anéis eritematosos e circulares concêntricos em forma de alvo, também conhecido como "olho de boi". O diagnóstico do EM é clínico e pode ser definido com a coexistência de lesões em alvo geralmente associado à infecção prévia ou atual por HSV, não necessitando de biópsia, quando a apresentação é típica. A biópsia pode auxiliar nos casos atípicos, como diagnósticos de exclusão. Considerações finais: o presente relato de caso demonstrou uma doença rara (estimado em 1,2-6 casos por milhão/ano), principalmente na faixa etária escolar. Além disso, teve uma apresentação atípica, tendo em vista a exuberância das lesões bolhosas.

Palavras-chave: Eritema Multiforme; Herpes Vírus; Criança.

\section{ABSTRACT}

Erythema multiforme (EM) is characterized by an immune reaction affecting skin and mucous most commonly observed after viral infections, especially caused by human herpesvirus (HSV). Case report: female, 8 years old, began with pain and edema in both hands. After the introduction of oxacillin therapy appeared vesicles and blisters on the chest, back and face, but mostly concentrated in hands and feet with involvement of palms and soles. The blisters were tense with erythematous base and some were crusty. Discussion: cutaneous lesions commonly appear in extremities such as hands and feet: they are flat, rounded, dark red and there are lesions in circular erythematous rings format, concentric, shaped target, also known as "bull's eye". EM diagnosis is clinical and can be set with the coexistence of target lesions and previous or current HSV infection, requiring no biopsy when the presentation is typical. Biopsy may help in atypical cases, as exclusion diagnoses. Closing remarks: this case report displayed a rare disease (estimated at 1.2 to 6 cases per million/ year), mainly on school-age children. Furthermore, it had an atypical presentation, in view of the bullous lesions.

Keywords: Erythema Multiforme; Herpes Viruses; Child.

\section{INTRODUČ̃̃}

O eritema multiforme (EM) caracteriza-se por uma reação imunológica, que afeta pele e mucosa, mais comumente observada após infecções virais, principalmente por herpes vírus (HSV). Porém, também vem sendo associada a algumas infecções bacterianas e parasitárias, a quadros pós vacinação contra hepatite $B$ e $B C G,{ }^{2}$ ao uso de alguns medicamentos e até mesmo a suplementos alimentares ${ }^{3}$ (Tabela 1). O quadro inicia com sinais prodrômicos, tais como mialgia, febre, artralgia e, posteriormente, evolui com erupções mucosas e, eventualmente, vesículas e ulcerações em pele. ${ }^{4}$ 
O EM tem maior prevalência em adultos jovens, com pico de idade entre os 20 r 40 anos, sem comorbidades e do sexo masculino. Entretanto, vale ressaltar que $20 \%$ dos casos ocorrem em crianças. ${ }^{2}$

Quanto à classificação, o EM pode ter 3 divisões de acordo com o grau de gravidade. O eritema menor, o maior ou Síndrome de Steven Johson (SSJ) e a $\mathrm{Ne}$ crólise Epidérmica Tóxica (NET). Alguns autores ainda preferem uma segunda divisão: as formas mais leves são classificadas como maior e menor, e as formas mais graves como SSJ e NET. ${ }^{5}$

O mecanismo etiológico exato do eritema multiforme não é definido; sabe-se que há uma reação de hipersensibilidade imunológica com a presença de células citotóxicas no epitélio, que induz a apoptose dispersa dos queratinócitos e necrose das células satélites. ${ }^{2}$

Desta forma, relatamos um caso clínico em que a apresentação desta patologia se deu de forma atípica com relação à morfologia das lesões.

Tabela 1 - Agentes que podem causar Eritema Multiforme. $2,4,6$

\begin{tabular}{ll}
\hline Antibióticos - 1 & Antimalárico - 1 \\
\hline - Clindamicina & - Cloriquina \\
- Amoxicilina & - Pirimetamina \\
- Ampicilina & \\
\hline - Minociclina & Sedativos - 1 \\
\hline - Fenalgésicos - 1 & - Amobarbital \\
\hline Vírus - 4 & - Pentobarbital \\
\hline - Vírus do herpes simples (HSV) & Aditivos alimentares \\
- Varicela zoster & - Nitrobenzenoto \\
- Citomegalovírus & \\
- Epstein barr & \\
- Adenovírus & \\
- Influenza & \\
\hline
\end{tabular}

\section{RELATO DE CASO}

Paciente feminina, 8 anos, iniciou com quadro de dor e edema em mãos. Após alguns dias, evoluiu com vesículas e bolhas em tronco, dorso (figura 4) e face (figura 1), mas em maior concentração em mãos (figura 2) e pés (figura 3), com acometimento de palmas e plantas. As bolhas eram tensas com base eritematosa e algumas com crosta. Associado às bolhas, havia pápulas difusas as quais se concentravam mais em dorso dos pés e região genital. A paciente encontrava-se em bom estado geral, com provas de função hepática normais, apresentando linfocitose apenas no início do quadro. Após a introdução de corticoide, as lesões evoluíram com formação de crosta, descamação e reepitelização.

Foram realizadas sorologias para Herpes com IgG não reagente e IgM reagente, evidenciando que era uma infecção recente.

A biópsia apresentou como resultado: dermatite vesicobolhosa com dano vacuolar de interface e necrose confluente de queratinócitos, bolha com conteúdo pustular e de queratinócitos necróticos. Achados compatíveis com eritema multiforme.

Finalmente, concluiu-se que a doença ocorreu

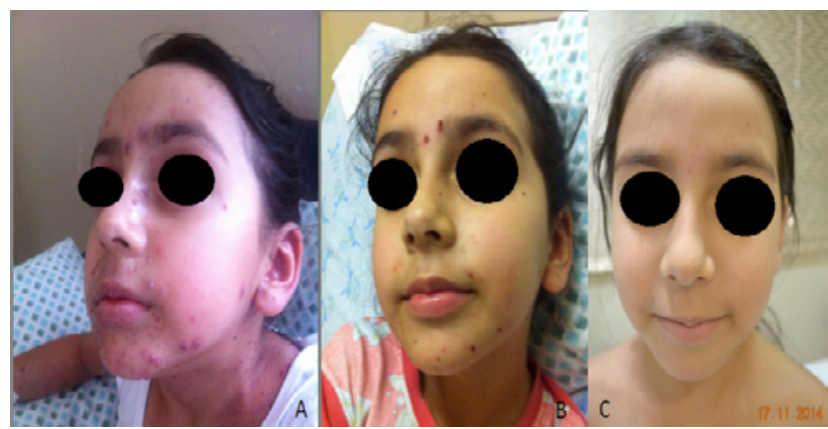

Figura 1 - Evolução das lesões em face: A) bolhas, B) crostas, C) máculas.

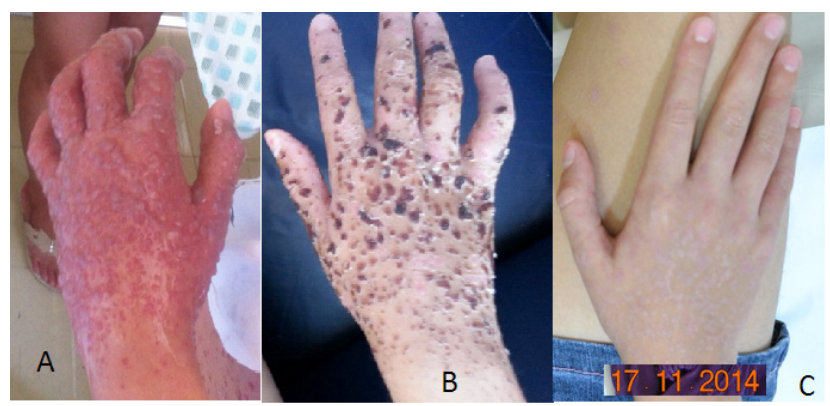

Figura 2 - Evolução das lesões em mãos: A) bolhas, B) crostas, C) máculas.

devido a uma infecção herpética subclínica, já que a paciente não apresentou sintomas típicos dessa infecção.

\section{DISCUSSÃO}

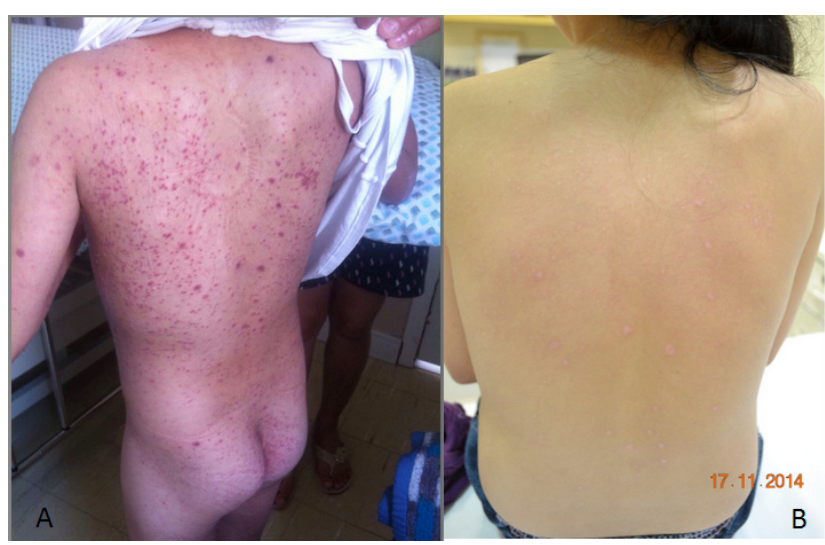

Figura 4 - Evolução das lesões em dorso: A) bolhas, pápulas e crostas, B) máculas.

As lesões cutâneas comumente aparecem em regiões de extremidades como mãos e pés: são planas, redondas e vermelho escuras, tendo o formato de anéis eritematosos e circulares concêntricos em forma de alvo, também conhecido como "olho de boi". Já, as lesões mucosas são placas eritematosas que sofrem necrose, que evoluem para ulceração com bordas irregulares. ${ }^{5}$ No caso relatado, as regiões mais intensamente acometidas foram as extremidades, conforme o descrito na literatura. Porém, as lesões iniciais eram vesiculares associadas a bolhas tensas com base eritematosa e algumas crostosas. A evolução completa ocorreu com 
formação de crosta, descamação e reepitelização, uma morfologia pouco frequente.

No que se refere à microscopia, a biópsia da zona edematosa da lesão-alvo pode mostrar um infiltrado inflamatório misto, com linfócitos, neutrófilos e, frequentemente, eosinófilos, agrupadas ou não no espaço perivascular. Pode estar associada uma vesiculação subepitelial com ceratinócitos basais necróticos, vista na biópsia da porção central da lesão. Além disso, os achados podem variar de acordo com a apresentação clínica, morfologia e tempo de evolução das lesões. ${ }^{2,6}$

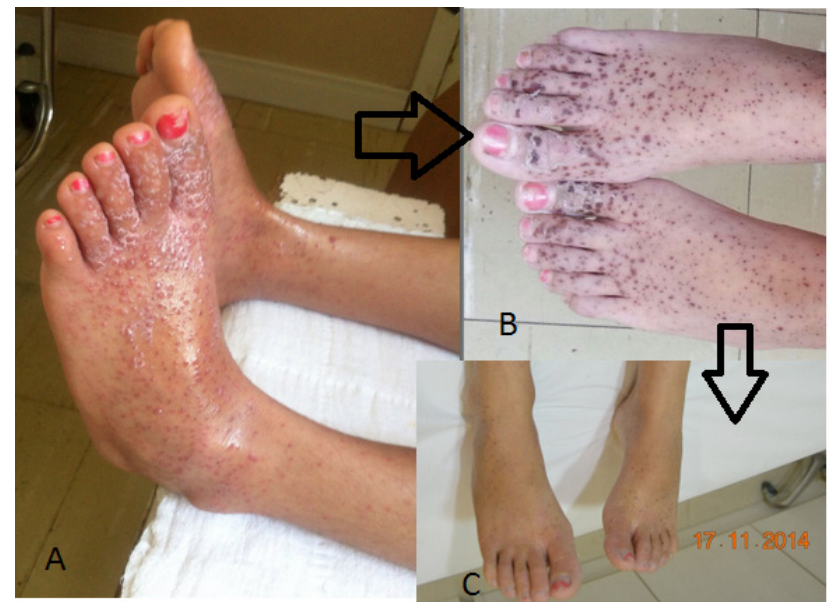

Figura 4 - Evolução das lesões em mãos: A) bolhas, B crostas, C) máculas.

O diagnóstico do EM é clínico e pode ser definido com a coexistência de lesões em alvo, geralmente associado à infecção prévia ou atual por HSV, não necessitando de biópsia, quando a apresentação é típica. A biópsia pode auxiliar nos casos atípicos, como diagnósticos de exclusão. Exames laboratoriais podem confirmar a infecção pelo HSV, porém não são necessários. ${ }^{6} \mathrm{O}$ diagnóstico diferencial inclui exantemas virais, reações de hipersibilidade, reações medicamentosas, urticária, vasculite urticariforme e erupção polimórfica à luz. As lesões em alvo mais escurecidas ou de cor purpúrica asssemelham-se à pitiríase rósea, lúpus eritematoso sistêmico, vasculite e eritema figurado. Quando as lesões bolhosas estão presentes, deve-se diferenciar de doenças autoimunes. ${ }^{6}$

O EM é uma doença autolimitada que, muitas vezes, não necessita tratamento. No entanto, medidas de suporte são importantes (anti-histamínicos, hidratação). O eritema multiforme menor pode responder a corticosteroides tópicos. Já, pacientes com eritema multiforme maior ou síndrome de Stevens Johnson podem requerer corticoides sistêmicos (prednisolona 0,5-1,0 mg/kg/dia por aproximadamente 7-10 dias) e/ou azatioprina ou outras drogas imunomoduladoras. Pode haver também, necessidade de internação hospitalar.
Pode haver necessidade de uso de antibióticos, como a tetraciclina, no caso de eritema multiforme associado ao M. pneumoniae ou aciclovir em casos relacionados ao vírus HSV. Se for detectado que o quadro esteja sendo causado por hipersensibilidade alérgica a medicamento; o mesmo deve ser descontinuado imediatamente. A paciente do caso relatado foi tratada com corticoide sistêmico, e medidas de suporte, em nível hospitalar, apresentando remissão completa das lesões de pele, sem nenhuma complicação. 5,6

Nas formas mais graves do eritema multiforme (SSJ e NET), o tratamento deve ser realizado em âmbito hospitalar, na Unidade de Terapia Intensiva, com ambiente aquecido e úmido, para se evitar traumas cutâneos e posterior infecção por patógenos. ${ }^{6}$

Os pacientes com EM tendem a apresentar bom prognóstico, uma vez que a doença é autolimitada com regressão em torno de 3 a 6 semanas. Porém, a taxa de recorrência é alta, cerca de $40 \%$ dos pacientes podem apresentar novo quadro de EM. ${ }^{6}$

\section{CONCLUSÃO}

O presente relato de caso demonstrou uma doença rara, principalmente na faixa etária escolar. Além disso, teve uma apresentação atípica, tendo em vista a exuberância das lesões bolhosas. No entanto, a evolução foi satisfatória devido ao diagnóstico rápido, realizado pela biópsia, e aos cuidados hospitalares de suporte providos à paciente.

É importante ressaltar que o EM é uma doença benigna e autolimitada, se tomados os devidos cuidados a fim de se evitar complicações infecciosas, pela grande debilidade da barreira imunológica mecânica da pele.

\section{REFERÊNCIAS}

1. Plaza, JA, Prieto, VG. Erythema Multiforme. Emedicine medscape, uptade set 15, 2014.

2. Carneiro SCA, Segundo AVL, Leal JLF, Vasconcelos BCE, Cardose COM. Eritema multiforme: relato de caso clínico. Rev. Cir. Traumatol. Buco-Maxilo-fac 2008; 8(2): 49-54.

3. Pauli CM, Silva CD, Putini C, Santos GM, Esteves EB, Carneiro RG, et al. Eritema Multiforme Relacionado ao uso de Suplemento Alimentar. Fundação Técnico Educacional Marques Souza.

4. Loureiro CCS, Adde CA, Perez FEG, Penha SS. Efeitos adversos de medicamentos tópicos e sistêmicos na mucosa bucal. Rev Bras Otorrinolaringol 2004; 70(1): 106-111. DOI: http://dx.doi.org/10.1590/S0034-72992004000100018.

5. Martinez R.S, Andrade DMR, Scabar LF, Giovani EM. A abordagem dos aspectos atuais do eritema multiforme e a Odontologia. J Health Sci Inst 2010; 28(3): 251-254.

6. Lamourex MR, Sternbach MR, Hsu TW. Erythema Multiforme. Am Fam Physician 2006; 74(11): 1883-1888. 